\title{
Psychiatric disorders and headache familial recurrence: a study on 200 children and their parents
}

\author{
Federica Galli • Loredana Canzano • \\ Teresa Gloria Scalisi · Vincenzo Guidetti
}

Received: 17 July 2008/Accepted: 31 January 2009/Published online: 8 April 2009

(C) Springer-Verlag 2009

\begin{abstract}
The main aim of the study was to examine the relationship between headache and familial recurrence of psychiatric disorders in parents and their children. Headache history and symptomatology have been collected in a clinical sample of 200 patients and their families, using a semi-structured interview (ICHD-II criteria). Psychiatric comorbidity was assessed by DSM-IV criteria. Chi squares and a loglinear analysis were computed in order to evaluate the main effects and interactions between the following factors: frequency and headache subtypes (migraine/notmigraine) in children, headache (migraine/not-migraineabsent/present) in parents, headache (absent/present) in grandparents, and psychiatric comorbidity (absent/present) have been analyzed: 94 mothers $(47 \%)$ and 51 fathers $(25.5 \%)$ had at least one psychiatric disorder, mainly mood and anxiety disorders. Considering the significant prevalence of Psi-co in children $(P<0.0001)$, we compared it with the presence of familiarity to headache: a significant interaction has been found $(P<0.05)$ showing that migraineurs with high familial recurrence of headache had a higher percentage $(74.65 \%)$ of psychiatric disorders, than no-migraineurs $(52.17 \%)$. Absence of headache familial loading seems to be related to psi-co only in no-migraine
\end{abstract}

F. Galli $(\bowtie) \cdot$ L. Canzano · V. Guidetti

Department of Child and Adolescent Neurology,

Psychiatry and Rehabilitation,

University of Rome "La Sapienza",

Via dei Sabelli, 108-00185 Rome, Italy

e-mail: federica.g@uniroma1.it

V. Guidetti

e-mail: vincenzo.guidetti@uniroma1.it

T. G. Scalisi

Department of Developmental and Social Psychology,

University of Rome "La Sapienza”, Rome, Italy headache ( 87.5 vs. $45.5 \%)$. The occurrence of psychiatric disorders is high in children with headache, but a very different pattern seems to characterize migraine (familial co-transmission of migraine and Psi-Co?) if compared with non-migraine headache.

Keywords Headache · Child · Family · Genetic . Psychiatric disorders - Anxiety and depression

\section{Introduction}

Headache with onset in childhood represents an unique opportunity to study headache disorders within a short time of their onset, allowing close monitoring of the child's environment (family, school, etc.), the interviewing of parents (e.g. on their own headache, personal clinical history, child's personality characteristics, headache symptoms), and so on.

Migraine is a complex, polygenic, and multifactorial disease, wherein genetics and biology interact with environmental factors. The candidate genes, the mechanisms involved are yet speculative [1-3].

The field of genetics of migraine has made considerable progress in the last year [3-7]. Recent discoveries include many novel mutations in the hemiplegic migraine gene ATP1A2.

The interplay of genetic and environmental factors has been stressed for explaining the occurrence of migraine without aura $[8,9]$. The current international system for headache classification [International Classification of Headache Disorders (ICHD-II)] does not consider the positive familial history as a criterion for the diagnosis of migraine, because there is no evidence to substantiate it as diagnostic parameter. However, the familial recurrence of 
migraine is well recognized [10-14], and previously considered as diagnostic criterion.

Indeed, cases of migraine in the family vary between 37 and $91 \%$ in probands with migraine and between 5 and $26 \%$ in probands without migraine [7].

All twin studies showed so far that migraine has a genetic component in addition to environmental factors $[15,16]$. Monozygotic twins show roughly twice the concordance rates than dizygotic twins [17], even if the concordance never reaches $100 \%$, indicating the importance of genes, but stressing the role of environmental factors as well. This is true across different countries [16].

Headache is a complex symptom, the result of interaction between genetic, biological and environmental factors. This complexity necessitates complex methodology to define and study headache. To date, the study of migraine has involved mainly genetic (e.g. identification of candidate genes), neurophysiological (e.g. cortical excitability), biological (e.g. measuring of chemical levels of neurotransmitters, platelets levels) or psychological (e.g. psychiatric comorbidity, personality characteristics) approaches; the challenge in the immediate future is to understand how these different factors are related in causing, triggering, characterizing, and/or maintaining migraine over time.

The complexity of migraine needs to hold a complex view. The likelihood that in many cases migraine is related to genetic factors, and in other cases to "environmental" factors, need clarification. What do "environmental factors" mean? It seems that all "non-genetic" are "environmental" factors, but differences should be clarified. The study of environmental factors might add elements in order to explain how non-genetic factors work on the biological level. However, the meaning of "environmental factors" needs to be clarified. If "environmental" means "not genetic", a wide range of different factors may be not only the triggers of headache, but causative (etiological) factors as well. If we consider migraine as the common end-point from different "causative" starting points, we need to explore if and what factors may be involved from the history of patients.

Twin data showed that the genetic liability to migraine is about $40-60 \%$, and the contribution of non-shared environmental factors range from 35 to 55\% [18-20].

If the study of genetic factors may give information on the ways of transmission of headache in family (even if up to now, it was impossible to find any particular model of transmission for migraine), studies of environmental factors are critical for obtaining data on the half of cases where genes are strongly supposed not being involved in the etiology of headache. It is well known that headache is frequently accompanied by physical and psychiatric complaints. The association between headache and anxiety and depression has been extensively explored [21-23] and no more a matter of debate. However, we do not know the mechanism(s) and direction of such a relationship crossing primary headache.

The main aim of this study is to analyze if a relationship exists between headache and psychiatric (anxiety and mood) disorders in children and their parents.

\section{Materials and methods}

\section{Sample}

Four-hundred clinical charts had been revised according to ICHD-II criteria 2004 [24]. Patients have been recruited at the Child and Adolescent Headache Center of the Department of Neurological, Psychiatric and Rehabilitative Sciences of the University of Rome "La Sapienza". Inclusion criteria:

a. Headache for the past 6 months at least,

b. consanguinity, and

c. willingness of both parents to be interviewed

Exclusion criteria

a. Absence of comorbid epilepsy,

b. secondary headache, and

c. Rare headache disorders (e.g. Alice in the Wonderland syndrome, ophtalmoplegic migraine, and so on)

A total of 200 families were enrolled in the study: 92 males (m.a. 10.82 years, SD 2.88, headache onset 7.6 years, SD 2.93, range 8-18) and 108 females (m.a. 11.13 years, SD 3.31, headache onset 7.7 years, SD 2.88; range 8-18).

Mothers' mean age was 40.77 years (SD 5.28). Fathers' mean age was 43.7 years (SD 6.07).

\section{Methodology}

To record headache history and symptomatology we used a semi-structured interview which covered all items required for diagnosing headache according to ICHD-II criteria [24]. The questionnaire did not replace medical examination and instrumental investigations. Blood examinations, urine-analysis, and EEG recordings were performed in the whole sample. Cardiology and otolaryngology examinations, ophthalmic tests, NMR, and CT scan were required in presence of specific indications.

The questionnaire was composed by different sections, in which we asked for biographic data, duration of headache history, frequency of headache, duration, location, quality and intensity of headache, the influence of physical activity, the occurrence of nausea, vomiting, photophobia 
and phonophobia, and the occurrence of other neurological symptoms. The interview was based on the child, mother, and/or father's report. To exclude an underlying organic disease the patients underwent an obligatory neurological and optional medical, ophthalmologic, and other different examinations. In some subjects, EEG, CT scan, or NMR were performed as well.

Moreover, the questionnaire covered the personal situation of the patient in family, school and leisure activities, severe health problems of sibling and parents, the family history of life-events, absence from school due to headache, and several other factors.

Data were also collected on the occurrence of headache in other relatives (grandfathers and grandmothers). Unfortunately, this kind of information was collected directly only in a few percentage of cases and is biased by the parents' personal view and memory. It means that the diagnoses in second degree relatives may be underestimated and/or misclassified [25], but data were only considered in a second step of our analysis.

Data on patients' siblings had not been collected, because their young age did not give guarantee on the later development or not of headache.

The questionnaire was filled out by the accompanying adult (mainly the mothers).

Two children were excluded from the analyses because they had cluster headache and chronic migraine.

Patients were directly interviewed, and the accompanying parents (when it needed) were interviewed for additional information.

When the accompanying parent was alone, we called by phone the other one to interview directly him/her on his/her headache characteristics and personal history.

The main topics of the questionnaire were:

- Complete clinical record to collect patients and parents' anamnesis;

- remote pathological anamnesis: questions about patients' prenatal, perinatal and post-natal period, with particular attention to infancy's pathologies;

- headache section: items to describe headache (frequency, intensity, location, etc.) to fulfill diagnosis according to IHS criteria (2004);

- Psychiatric diagnoses by DSM-IV criteria.

In the questionnaire there are

- Yes-No items: for questions about the presence or absence of perinatal suffering; menarche; premenstrual syndrome; benign paroxysmal vertigo; seizures; othorhinolaryngological disturbances; visual disturbances; aura presence; clinical examinations and instrumental investigations; prophylactic and acute attacks therapy; interruption of school attendance due to headache.
- Multiple choice items: about number of attacks; duration; quality of pain; intensity; aura symptoms; accompanying symptoms; periodicity of attacks; usual days of the week; usual time of head pain beginning; lateralization; location of start; triggering factors; relieving factors; worsening factors.

- Open answer items: in case of questions about family anamnesis (mother, father, collaterals on mother's side, collaterals on father's side); presence of life-events; pregnancy; delivery; perinatal suffering's type; sleepwake cycle; lactation; weaning; psychological development; sphincters; schooling; allergic disturbances; other pathologies.

\section{Statistical analysis}

The following categorical variables were considered in data analysis: headache sub-type in children [migraine or other headache sub-types (oHs)], psychiatric comorbidity in children (present, absent), headache familial recurrence (absent, only in parents, only in grandparents, both in parents and grandparents), intensity of pain (low, medium or high), frequency of crises $(1-3 /$ month $=1 ; 1 /$ week $=2$; $>4 /$ month $=3$ ) and Psychiatric disorders in parents (present, absent). In the case the child has at least one parent and at least one grandparent with headache, we labeled the situation as "double familial loading" (second step of the study). Under the term "psychiatric disorders" or "psychiatric comorbidity", we collected any psychiatric disorder diagnosed both in parents and children, even though in $85 \%$ of the cases they were diagnoses of anxietymood disorders' spectrum. For statistical purposes, we decided to simplify all variables in dichotomous categories (present/absent).

Statistical package for the social science (SPSS 15.0) software (SPSS Inc., Chicago, IL, USA) was used in performing statistical analyses. Two-way frequency tables were analyzed by means of person Chi-square $\left(\chi^{2}\right)$ tests; multi-way frequency tables were examined through loglinear analysis.

\section{Results}

Headache sub-types, psychiatric comorbidity and headache familial recurrence in the total sample

Migraine and oHs children in the total sample $(N=198)$ were $138(69.7 \%)$ and $60(30.3 \%)$, respectively. Two children with cluster headache were excluded. Psychiatric comorbidity was present in 129 children $(65.2 \%$ of the total sample). Headache familial recurrence was absent in 19 
children (9.6\%); it was present only in parents of 63 children $(31.8 \%)$, only in grandparents of 19 children $(9.6 \%)$ and both in parents and grandparents of 97 children $(49.0 \%)$. Psychiatric disorders in parents were reported in 115 cases $(58.1 \%)$.

Differences between migraine and oHs children with respect to the other variables were assessed by means of Pearson $\chi^{2}$ tests. Type of headache in children was not associated with psychiatric comorbidity $\left(\chi^{2}=1.01 ; d f=\right.$ $1 ; P>0.05)$, or with headache familial recurrence $\left(\chi^{2}=4.25 ; d f=2 ; P>0.05\right)$. A difference was found for the incidence of psychiatric disorders in parents, present for $63.8 \%$ of migraine children and $45 \%$ of $\mathrm{oHs}$ ones $\left(\chi^{2}=6.05 ; d f=1 ; P<0.05\right)$.

Multi-way association between headache sub-type, psychiatric comorbidity and headache familial recurrence

The aim of the second part of the analysis was to verify the presence of associations between the variables involved in the present study, considering them simultaneously in a loglinear model. Given the high number of cells resulting from the original $2 \times 2 \times 4 \times 2$ design (see "Statistical analysis"), only two categories were considered for the headache familial recurrence variable, that is "absent" and "double" (both in parents and grandparents). The $2 \times 2 \times 2 \times 2 \times 3$ resulting design involved 116 participants (85 migraine and $31 \mathrm{oHs}$ children) from the total sample and contained the following variables: headache type in child (migraine, oHs), psychiatric comorbidity in child (present, absent), headache familial recurrence (absent, double), psychiatric disorders in parents (present, absent) and frequency $(1-3 /$ month $=1 ; 1 /$ week $=2 ;>4$ / month $=3$ ).

All two-way contingency tables between the four categorical variables provided expected frequencies in excess of five, preventing power reduction risk given by inadequacy of expected frequencies [26].

Table 1 shows significant main effects and interactions resulting from the loglinear analysis performed on the design variables. A hierarchical model was tested including the two significant interactions reported in Table 1 ("headache type in child $\times$ psychiatric disorders in parents" and "headache type in child $\times$ psychiatric comorbidity in child $\times$ headache familial recurrence") and all the lower-order effects they contain. The model had a likelihood ratio $\chi^{2}=7.57(d f=6 ; P=0.271)$, indicating a good fit between observed and expected frequencies generated by the model (see Table 3 ).

Table 2 shows a hierarchical model tested including more two significant interactions $(P<0.05)$ and one almost significant $(P=0.06) \quad$ ("headache type in
Table 1 Partial associations tests on headache type in child (HTC), psychiatric comorbidity in child (PCC), headache familial recurrence (HFR) and psychiatric disorders in parents (PDP)

\begin{tabular}{lccc}
\hline Effect name & $d f$ & Partial Chisq & $P$ \\
\hline HTC & 1 & 26.14 & $<0.0001$ \\
PCC & 1 & 17.12 & $<0.0001$ \\
HFR & 1 & 57.36 & $<0.0001$ \\
PDP & 1 & 6.83 & $<0.01$ \\
HTC $\times$ PDP & 1 & 7.81 & $<0.01$ \\
HTC $\times$ PCC $\times$ HFR & 1 & 6.68 & $<0.01$ \\
Hierarchial model selected: HTC $\times$ PDP + HTC $\times$ PCC $\times$ HFR, \\
$\quad$ likelihood ratio $\chi^{2}=7.57 ; d f=6 ; P=0.271$ \\
\hline
\end{tabular}

child $\times$ frequency"; "psychiatric comorbidity in child $\times$ frequency" and "psychiatric disorders in parents $\times$ frequency"). The variable intensity of pain (low, medium or high) has been considered, but no main effects or significant interactions with other variables has been evidenced. The model had a likelihood ratio $\chi^{2}=11.66(d f=11$; $P=0.390)$. This different loglinear analysis has been realized on the whole sample $(N=198)$.

Model parameter estimates are reported in Table 4; each probability value refers to the deviation between the corresponding cell and the contrast cell (that is the zeroparameter in each block of cells in the table).

Figure 1 shows percentage count for observed frequencies in the two-way interaction included in the model (headache type in child $\times$ psychiatric disorders in parents; partial $\left.\chi^{2}=7.807 ; d f=1 ; P<0.01\right)$. Percentages are calculated separately for migraine and oHs groups. As in the total sample, the presence of psychiatric disorders in parents is prevalent in migraine group $(70.59 \%)$ compared to oHs one (38.71\%); this difference is significant as shown in the upper part of table $4(z=5.35 ; P<0.001)$ and represents the most relevant contribution to the interaction, given that it produces the highest parameter estimate (2.12).

Table 5 shows a hierarchical model including as variable frequency of attacks in child. Particularly, in the upper part of table 5, there was an interaction between presence/ absence of psychiatric comorbidity in child and different frequency of crisis $(P<0.001)$. Moreover, in the middle of table 5 was shown a significant interaction between headache type in child and Frequency $(P<0.001)$.

Figure 2 shows percentage count for observed frequencies in the three-way interaction included in the model (headache type in child $\times$ psychiatric comorbidity in child $\times$ headache familial recurrence; partial $\chi^{2}=6.675$; $d f=1 ; P<0.01)$. Percentages are calculated separately for migraine and oHs groups. The presence of psychiatric comorbidity is prevalent both in migraine- $(71.76 \%)$ and 
Table 2 Partial associations tests on headache type in child (HTC), psychiatric comorbidity in child (PCC), psychiatric disorders in parents (PDP) and frequency (FREQ) $(N=198)$

\begin{tabular}{lccl}
\hline Effect name & $d f$ & Partial Chisq & $P$ \\
\hline HTC & 1 & 31.58 & $<0.0001$ \\
PCC & 1 & 18.47 & $<0.0001$ \\
PDP & 1 & 5.19 & $<0.05$ \\
FREQ & 2 & 99.20 & $<0.0001$ \\
HTC $\times$ PDP & 1 & 7.29 & $<0.01$ \\
HTC $\times$ FREQ & 2 & 6.55 & $<0.05$ \\
PCC $\times$ FREQ & 2 & 5.52 & $=0.06$ \\
PDP $\times$ FREQ & 2 & 6.94 & $<0.05$ \\
Hierarchical model selected: HTC $\times$ PDP + HTC $\times$ FREQ + PCC $\times$ FREQ + PDP $\times$ FREQ, \\
likelihood ratio $\chi^{2}=11.66 ; d f=11 ; P=0.390$ & \\
\hline
\end{tabular}

Table 3 Hierarchical model of headache type in child, psychiatric comorbidity in child, psychiatric disorders in parents and frequency (1-3/ month $=1 ; 1 /$ week $=2 ;>4$ /month $=3)(N=198)$

\begin{tabular}{|c|c|c|c|c|c|c|c|c|}
\hline Headache type in child & $\begin{array}{l}\text { Psychiatric comorbidity } \\
\text { in child }\end{array}$ & $\begin{array}{l}\text { Psychiatric disorders } \\
\text { in parents }\end{array}$ & FREQ & Obs. Count ${ }^{\mathrm{a}}$ & $\%$ & Exp. count ${ }^{b}$ & $\%$ & Standard. residuals ${ }^{\mathrm{c}}$ \\
\hline \multirow[t]{12}{*}{ Migraine } & \multirow[t]{6}{*}{ Absent } & \multirow[t]{3}{*}{ Absent } & 1 & 9.0 & 4.5 & 7.35 & 3.7 & 0.61 \\
\hline & & & 2 & 5.0 & 2.5 & 4.08 & 2.1 & 0.45 \\
\hline & & & 3 & 7.0 & 3.5 & 7.09 & 3.6 & -0.04 \\
\hline & & \multirow[t]{3}{*}{ Present } & 1 & 10.0 & 5.1 & 11.68 & 5.9 & -0.49 \\
\hline & & & 2 & 1.0 & 0.5 & 2.04 & 1.0 & -0.73 \\
\hline & & & 3 & 13.0 & 6.6 & 16.62 & 8.4 & -0.89 \\
\hline & \multirow[t]{6}{*}{ Present } & \multirow[t]{3}{*}{ Absent } & 1 & 8.0 & 4.0 & 8.48 & 4.3 & -0.17 \\
\hline & & & 2 & 5.0 & 2.5 & 5.25 & 2.7 & -0.11 \\
\hline & & & 3 & 16.0 & 8.1 & 17.74 & 9.0 & -0.41 \\
\hline & & \multirow[t]{3}{*}{ Present } & 1 & 14.0 & 7.1 & 13.48 & 6.8 & 0.14 \\
\hline & & & 2 & 3.0 & 1.5 & 2.63 & 1.3 & 0.23 \\
\hline & & & 3 & 47.0 & 23.7 & 41.55 & 21.0 & 0.85 \\
\hline \multirow[t]{12}{*}{$\mathrm{oHs}$} & \multirow[t]{6}{*}{ Absent } & \multirow[t]{3}{*}{ Absent } & 1 & 5.0 & 2.5 & 4.25 & 2.1 & 0.36 \\
\hline & & & 2 & 0.0 & 0.0 & 0.73 & 0.4 & -0.85 \\
\hline & & & 3 & 10.0 & 5.1 & 6.34 & 3.2 & 1.46 \\
\hline & & \multirow[t]{3}{*}{ Present } & 1 & 2.0 & 1.0 & 2.71 & 1.4 & -0.43 \\
\hline & & & 2 & 1.0 & 0.5 & 0.15 & 0.1 & 2.23 \\
\hline & & & 3 & 6.0 & 3.0 & 5.95 & 3.0 & 0.02 \\
\hline & \multirow[t]{6}{*}{ Present } & \multirow[t]{3}{*}{ Absent } & 1 & 3.0 & 1.5 & 4.91 & 2.5 & -0.86 \\
\hline & & & 2 & 1.0 & 0.5 & 0.94 & 0.5 & 0.07 \\
\hline & & & 3 & 14.0 & 7.1 & 15.84 & 8.0 & -0.46 \\
\hline & & \multirow[t]{3}{*}{ Present } & 1 & 5.0 & 2.5 & 3.13 & 1.6 & 1.06 \\
\hline & & & 2 & 0.0 & 0.0 & 0.19 & 0.1 & -0.43 \\
\hline & & & 3 & 13.0 & 6.6 & 14.88 & 7.5 & -0.49 \\
\hline
\end{tabular}

\footnotetext{
${ }^{a}$ Observed frequencies

${ }^{\mathrm{b}}$ Expected frequencies

c Standardized residuals
}

oHs children $(61.29 \%)$; at the same time, double headache familial recurrence is also prevalent in both groups (87.06\% for migraine and $74.19 \%$ for oHs children). The main difference between the groups is due to the stronger association in migraine children between psychiatric comorbidity and double headache familial recurrence (64.71\%) compared to the oHs group (38.71\%).

The inspection of parameter estimates for this interaction (see the middle and lower parts of Table 4) shows that the highest $z$ values come from migraine group (middle 
Table 4 Hierarchical model of headache type in child, psychiatric comorbidity in child, headache familial recurrence and psychiatric disorders in parents

\begin{tabular}{|c|c|c|c|c|c|c|c|}
\hline $\begin{array}{l}\text { Headache type } \\
\text { in child }\end{array}$ & $\begin{array}{l}\text { Psychiatric comorbidity } \\
\text { in child }\end{array}$ & $\begin{array}{l}\text { Headache familial } \\
\text { recurrence }\end{array}$ & $\begin{array}{l}\text { Psychiatric disorders } \\
\text { in parents }\end{array}$ & Parameter estimate $^{\mathrm{a}}$ & SE & $z$ value & $P$ \\
\hline \multirow[t]{2}{*}{ Migraine } & - & - & Absent & 1.25 & 0.43 & 2.93 & $<0.01$ \\
\hline & - & - & Present & 2.12 & 0.40 & 5.35 & $<0.001$ \\
\hline \multirow[t]{2}{*}{$\mathrm{OHs}$} & - & - & Absent & 0.46 & 0.37 & 1.25 & $=0.213$ \\
\hline & - & - & Present & 0.00 & & & \\
\hline \multirow[t]{4}{*}{ Migraine } & Absent & Absent & - & -2.40 & 0.47 & -5.13 & $<0.001$ \\
\hline & & Double & - & -1.06 & 0.27 & -3.99 & $<0.001$ \\
\hline & Present & Absent & - & -2.22 & 0.43 & -5.15 & $<0.001$ \\
\hline & & Double & - & 0.00 & & & \\
\hline \multirow[t]{5}{*}{$\mathrm{oHs}$} & Absent & Absent & - & -2.49 & 1.04 & -2.39 & $<0.05$ \\
\hline & & Double & - & -0.09 & 0.42 & -0.21 & $=0.835$ \\
\hline & Present & Absent & - & -0.54 & 0.48 & -1.13 & $=0.257$ \\
\hline & & Double & - & 0.00 & & & \\
\hline & & & Constant & 1.54 & 0.37 & 4.19 & $<0.001$ \\
\hline
\end{tabular}

${ }^{a}$ Aliased (or redundant) parameters are set to zero and are used as contrast values for $z$ tests

part of Table 4). In particular, the cell, mainly contributing to the interaction, is given by the association between migraine, presence of psychiatric comorbidity and double headache familial recurrence. In fact parameters in the other three cells regarding migraine children indicate that frequencies are significantly lower (negative $z$ values and $P<0.001$ ) when only psychiatric comorbidity is present, only double headache familial recurrence is present or when both characteristics are absent. The observed frequencies (in percentages) relative to the significant differences described are displayed in Fig. 2a.

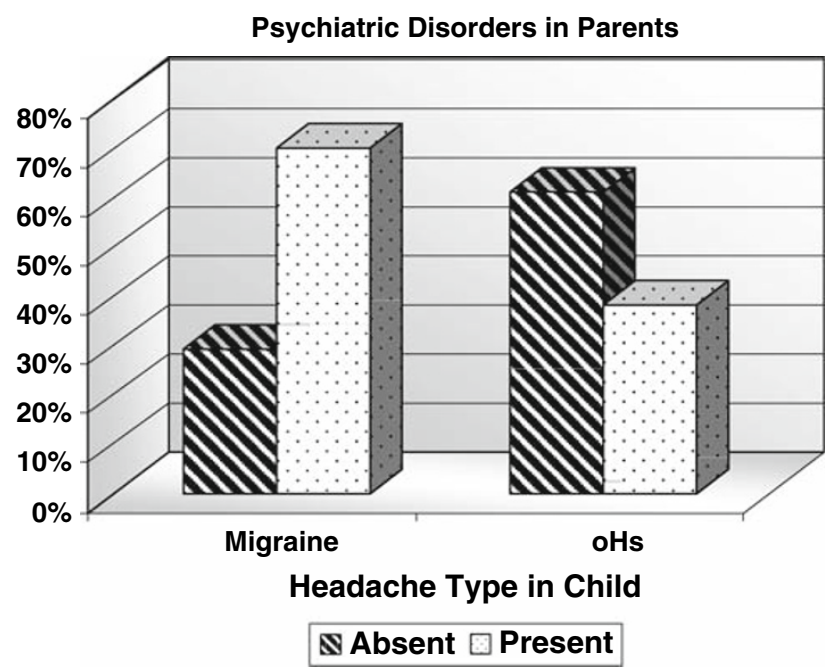

Fig. 1 Headache type in child $\times$ psychiatric disorders in parents. Percentage count for observed frequencies in headache type in child $\times$ psychiatric disorders in parents interaction. Partial $\chi^{2}=7.807 ; d f=1 ; P<0.01$. Percentages are calculated separately for migraine and oHs groups
Differences among oHs children are smaller than those found among migraine group (see $z$ values in the lower part of Table 4 and percentages in Fig. 2b). Parameter estimate inspection reveals that psychiatric comorbidity in oHs children and double headache familial recurrence occur together or separately with the same frequency (see not significant $z$ values for second and third cells in oHs group in Table 4), while the absence of both characteristics results significantly less frequently compared to the remaining combinations $(z=-2,39 ; P<0.05)$.

Figure 3 shows percentage count for observed frequencies in the psychiatric comorbidity in child $\times$ frequency (partial $\chi^{2}=5.52 ; d f=2 ; P=0.06$ ). Percentages are calculated separately for psychiatric comorbidity groups. In Fig. 4, we can observe an interaction between headache type in child and frequency of the crises (partial $\chi^{2}=6.55$; $d f=2 ; P<0.05$ ). Moreover, in Fig. 4 percentage count for observed frequencies in psychiatric disorders in parents $\times$ frequency interaction was almost significant (partial $\left.\chi^{2}=6.94 ; d f=2 ; P=0.05\right)$. Percentages are calculated separately for each group.

\section{Discussion}

In the present study only $9.6 \%$ of patients did not have familial recurrence of headache, with a half of the sample (49\%) showing both parents and grandparents complaining of headache (double familial loading). The occurrence of headache in family members strongly suggests a genetic transmission of headache, but it is not sufficient to close the debate. The child grows up in an environment where 
Table 5 Hierarchical model of headache type in child, psychiatric comorbidity in child, headache familial recurrence and psychiatric disorders in parents

\begin{tabular}{|c|c|c|c|c|c|c|c|}
\hline $\begin{array}{l}\text { Headache type } \\
\text { in child }\end{array}$ & $\begin{array}{l}\text { Psychiatric comorbidity } \\
\text { in child }\end{array}$ & $\begin{array}{l}\text { Psychiatric disorders } \\
\text { in parents }\end{array}$ & Frequency & Parameter estimate $^{\mathrm{a}}$ & SE & $z$ value & $P$ \\
\hline \multirow[t]{3}{*}{-} & \multirow[t]{3}{*}{ Absent } & \multirow[t]{3}{*}{-} & 1 & -1.70 & 0.39 & -4.35 & $<0.001$ \\
\hline & & & 2 & -4.62 & 0.92 & -5.04 & $<0.001$ \\
\hline & & & 3 & -0.92 & 0.20 & -4.65 & $<0.001$ \\
\hline \multirow[t]{3}{*}{-} & \multirow[t]{3}{*}{ Present } & \multirow[t]{3}{*}{-} & 1 & -1.56 & 0.38 & -4.06 & $<0.001$ \\
\hline & & & 2 & -4.37 & 0.90 & -4.86 & $<0.001$ \\
\hline & & & 3 & 0.00 & & & \\
\hline \multirow[t]{3}{*}{ Migraine } & \multirow[t]{3}{*}{-} & \multirow[t]{3}{*}{-} & 1 & 1.46 & 0.36 & 4.10 & $<0.001$ \\
\hline & & & 2 & 2.64 & 0.81 & 3.27 & $<0.001$ \\
\hline & & & 3 & 1.03 & 0.24 & 4.31 & $<0.001$ \\
\hline \multirow[t]{3}{*}{$\mathrm{oHs}$} & \multirow[t]{3}{*}{-} & \multirow[t]{3}{*}{-} & 1 & 0.00 & & & \\
\hline & & & 2 & 0.00 & & & \\
\hline & & & 3 & 0.00 & & & \\
\hline \multirow[t]{3}{*}{-} & \multirow[t]{3}{*}{-} & \multirow[t]{3}{*}{ Absent } & 1 & 0.45 & 0.36 & 1.24 & $=0.21$ \\
\hline & & & 2 & 1.61 & 0.62 & 2.60 & $<0.01$ \\
\hline & & & 3 & 0.06 & 0.28 & 0.23 & $=0.82$ \\
\hline \multirow[t]{3}{*}{-} & \multirow[t]{3}{*}{-} & \multirow[t]{3}{*}{ Present } & 1 & 0.00 & & & \\
\hline & & & 2 & 0.00 & & & \\
\hline & & & 3 & 0.00 & & & \\
\hline \multirow[t]{2}{*}{ Migraine } & \multirow[t]{2}{*}{-} & Absent & - & -0.91 & 0.32 & -2.82 & $<0.01$ \\
\hline & & Present & & 0.00 & & & \\
\hline \multirow[t]{3}{*}{$\mathrm{oHs}$} & \multirow[t]{3}{*}{-} & Absent & - & 0.00 & & & \\
\hline & & Present & & 0.00 & & & \\
\hline & & & Constant & 2.70 & 0.22 & 12.51 & $<0.001$ \\
\hline
\end{tabular}

${ }^{\text {a }}$ Aliased (or redundant) parameters are set to zero and are used as contrast values for $z$ tests

headache may also represent a model of behavior to mimic. We did not find a correspondence between the sub-type of headache in children and headache familial recurrence.

The genetic transmission had been studied extensively in migraineurs, even if one study [27] evidenced that firstdegree relatives of probands with chronic tension-type headache had 3.1-fold significantly increased risk of chronic tension-type headache, hypothesizing a genetic component for this type of headache too. In synthesis, complex segregation analysis suggests a multifactorial inheritance for migraine with and without aura and chronic tension-type headache [28]. Our study stresses the importance of familial recurrence (mostly on maternal line) for migraine, but less for tension-type headache.

Not only migraine, but also psychiatric disorders run in families [29]. Psychiatric disorders, specifically anxiety and mood disorders, are particularly frequent in migraineurs and their relatives [29]. In our study psychiatric disorders are equally represented both in migraine and $\mathrm{oHs}$, but these findings are not new in literature [30,31]. The prevalence of anxiety and mood disorders is not specific of migraine, but it might be related to the recurrence of chronic pain disorders [32]. An aspect to take in mind, but still poorly understood, is that different kinds of chronic pain are related to the presence of psychiatric disorders (mainly anxiety and mood disorders) [33], opening diagnostic [34], treatment [35] and etiologic [36, 37] issues.

Noteworthy, in our study, parents of migraine children showed a significant higher comorbidity of psychiatric disorders than parents of children with oHs (Fig. 1). This aspect needs attention, because it is the first point clearly differentiating migraineurs from oHs, as we will better discuss below.

In the second part of our study, we found that migraine children are characterized by a higher prevalence of psychiatric disorders in parents, co-occurrence of psychiatric comorbidity and headache familial recurrence than oHs. Both psychiatric comorbidity and headache familial recurrence are very frequent in oHs children too, but they can occur together or alone. This pattern of results suggests that anxiety/depression and headache familial recurrence act as additive factors in oHs, while in migraine they might represent, together with psychiatric disorders in parents, interrelated aspects of a more complex relationship. It means that greater the weight of headache familial recurrence the more the possibility that the child shows psychiatric 
(a) Psychiatric Comorbidity in Migraine

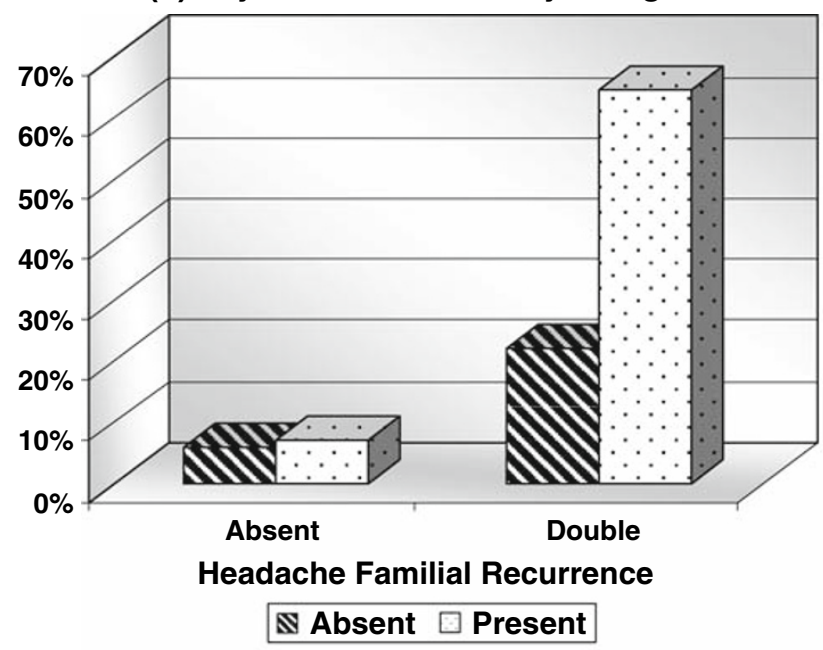

(b) Psychiatric Comorbidity in oHs

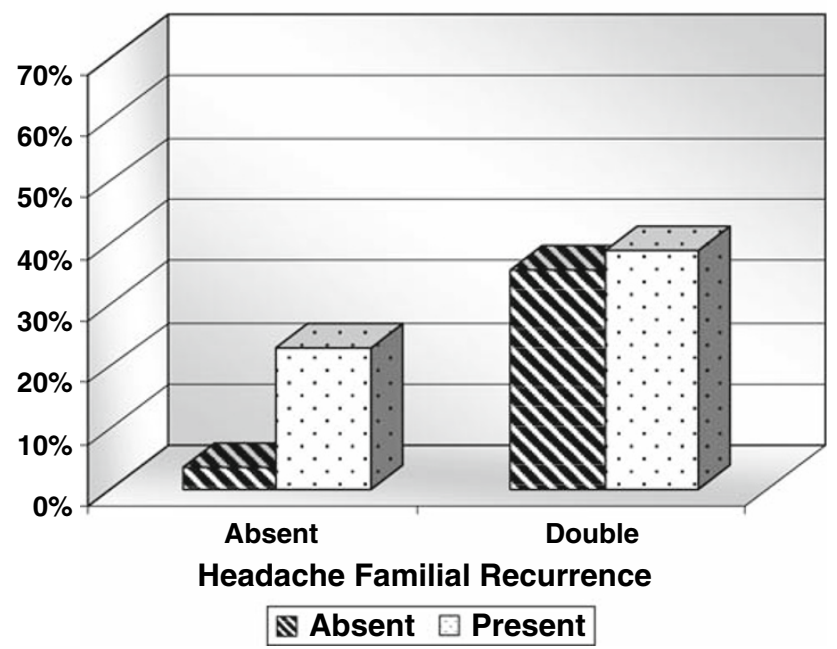

Fig. 2 Headache type in child $\times$ psychiatric comorbidity in child $\times$ headache familial recurrence. Percentage count for observed frequencies in headache type in child $\times$ psychiatric comorbidity in child $\times$ headache familial recurrence interaction. Partial $\chi^{2}=6.675$; $d f=1 ; P<0.01$. Percentages are calculated separately for migraine and oHs groups

comorbidity, but only in the case of migraine (Fig. 2). It may be speculated that a genetic co-transmission of anxiety and depression exists in migraineurs, while tension-type headache is more influenced by environmental factors. The hypothesis of genetic co-transmission of migraine, anxiety and depression has been advanced some time ago [29], and the evidence are coming in this direction [38].

Moreover, we found an interaction almost significant between psychiatric comorbidity in child and frequency of the crises, and a significant interaction between psychiatric comorbidity in parents and frequency of attacks in children (Figs. 3, 4). This important finding outlines the close interaction between psychiatric comorbidity and

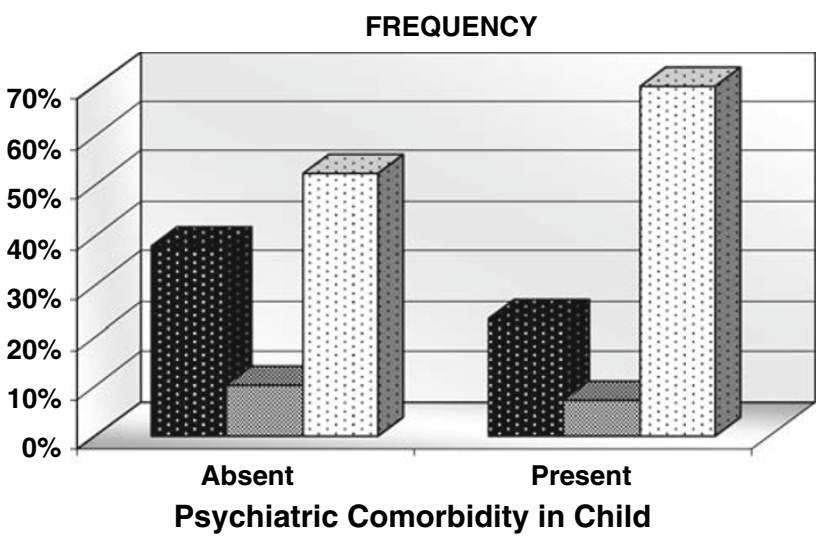

91:2@3

Fig. 3 Psychiatric comorbidity in child $\times$ frequency. Percentage count for observed frequencies in psychiatric comorbidity in child $\times$ frequency $(1-3 /$ month $=1 ; 1 /$ week $=2 ;>4 /$ month $=3)$ interaction. Partial $\chi^{2}=5.52 ; d f=2 ; P=0.06$. Percentages are calculated separately for psychiatric comorbidity groups

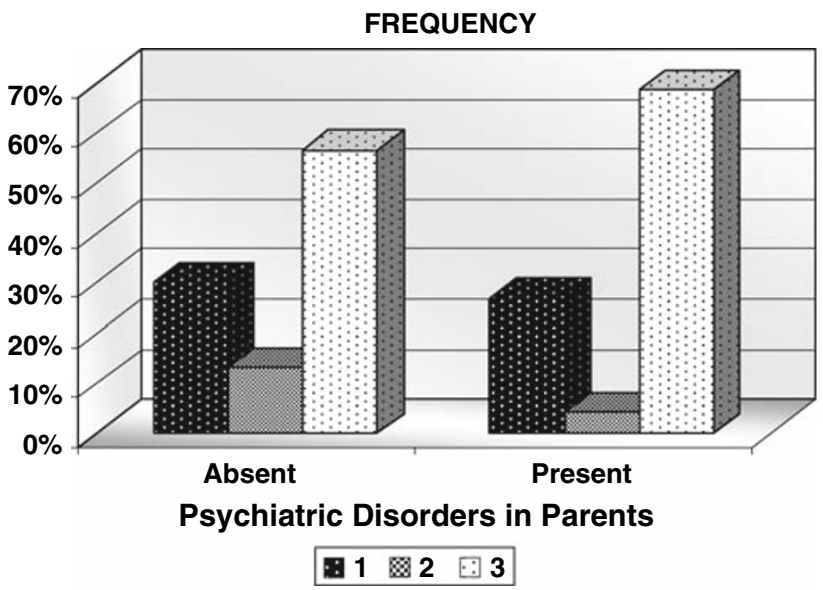

Fig. 4 Psychiatric disorders in parents $\times$ frequency. Percentage count for observed frequencies in psychiatric disorders in parents $\times$ frequency $(1-3 /$ month $=1 ; 1 /$ week $=2 ;>4 /$ month $=3)$ interaction. Partial $\chi^{2}=6.94 ; d f=2 ; P=0.05$. Percentages are calculated separately for each group

the chronification process, not only in patients, but in parents as well: we do not know if the mechanism is environmental or genetically linked.

Serotonin receptors and transporters as well as adrenaline have also been implicated in migraine and various mental health disorders [39, 40].Various biologically based studies have looked at the association between migraine and mental disorders. A particular dopamine D2 receptor genotype was found to be associated with migraine, major depression, generalized anxiety disorder, panic attacks and phobia [41]. Low tyramine conjugation, a marker of endogenous depression, was associated with a lifetime history of major depression in migraineurs compared with 
non migraineurs [42]. This finding ruled out the possibility that the depression was a psychological reaction to migraine attacks.

There are also numerous studies supporting the use of various antidepressants in the prevention or treatment of migraine including tricyclic antidepressants, anxiolytic, SNRI, and other forms of antidepressants [43].

Breslau and colleagues [44] recently replicated the finding of a bidirectional association between major depression and migraine and reported that major depression did not predict an increase in the incidence of the severe headache types. Oedegaard et al. found that patients with migraine aura without headache were different from patients having migraine headache plus aura concerning some important clinical characteristics. The patients that had migraine aura without headache had a low frequency of affective temperaments and a low probability of having made a suicide attempt, as well as a higher age of onset of migraine aura [45].

The bidirectional influence for migraine and major depression has been interpreted as suggesting a common genetic vulnerability for migraine and depression. Comorbid psychiatric disorders represent a modifiable risk factor in the transformation and chronification of migraine and tension-type headache. As suggested by Todd et al. [46] screening for depression and anxiety should be incorporated to assess for the presence of comorbid psychopathology. The role of high levels of stress susceptibility and somatic trait anxiety has been suggested to explain the evidence that old women, but not middle-aged ones, were more vulnerable to migraine pain, and, possibly, less able to cope with the pain [47].

Patterns of co-transmission of migraine and anxiety and depression have failed to reveal evidence for a genetic predisposition to migraine and major affective disorders $[29,48]$. It may be that a dysregulation in the brain's neurochemical system, possibly the serotoninergic system, increases an individual's vulnerability to anxiety and affective disorders as well as migraine [49]. Alternatively, it may be that each disorder increases the risk for the other disorder. For example, anxiety and mood disorders may be risk factors for transforming episodic into chronic headaches [30].

In Hung'study chronic depression, greater severity of depression, and female gender in major depressive disorder were risk factors associated with migraine or chronic daily headache. Major depressive disorder patients with any two risk factors might benefit from a headache evaluation. Chronic daily headache was associated with chronic depression or longer major depressive episodes. Therefore, early intervention to treat depression might prevent the developing of chronic depression and and chronic daily headache [50].
In addition, symptoms associated with anxiety and depression are more common in chronic than in episodic migraine and tension-type headache [51]. Patients with pure migraine, pure tension-type headache and combined migraine and tension-type headaches showed significant differences in the rate of occurrence of depression and anxiety subtypes, the latter being at higher risk of major depressive episodes and obsessive-compulsive disturbance [52]. There is still no definite evidence for the pathogenesis of the comorbid disorders, even if the most plausible hypothesis is that migraine shares some causative, genetical, biochemical or environmental factors with depression and panic attack disorder [53-55].

Moreover, a study of Lipchik et al. [55, 56] revealed that comorbid psychiatric conditions not only are commonly encountered by physicians who treat headache patients, but that such conditions may also render headache patients more refractory to intervention.

Detecting differences according to the presence/absence of anxiety and/or depression both in child patients and their parents may give interesting information on the existence of the suggested "syndromic" relationship between migraine and anxiety/depression [44, 57-59].

Even if various theories have been suggested to explain the association between migraine and various psychiatric comorbidities, more studies are needed to elucidate the mechanism of this association.

Thus, clinical and population studies evidence that migraine have significant psychiatric comorbidity [29]. At the present, it is not known why such comorbidity occurs, but several possibilities have been advanced, such as one disorder being the cause of the other, or shared biological and/or genetic factors. One line of study suggests the implication of a shared biological milieu involving neurotransmitters (e.g. serotonin) in both migraine and anxiety, mood disorders [60-63].

The underlying neurochemistry of many primary headache disorders, especially migraine, has much in common with the neurochemistry (indole and biogenic amines) of various psychiatric illnesses [64]. The elevated risk a patient with migraine or depression has of developing the other disorder seems related in most cases to shared underlying serotoninergic abnormalities of the CNS [65]. Even if association is the most common relationship between psychiatric illnesses and headache disorders, though, it does not preclude the possibility of a causal relationship in some conditions.

Indeed, this study has shortcomings to be considered. First, it is a clinical study and the possibility of self-selection of patients (and parents) according to a major severity of their conditions is to take in mind. However, the severity should be more related to migraine families than other headache sub-types. Another limitation is related to the 
simplification of variables that has been realized to raise the statistical power of the study. Further studies are warranted to cross specific diagnoses both in children and their parents, both on headache and psychiatric sides. Another shortcoming is represented by the collection of families' history in second-line relatives (grandparents), because it was not possible to realize a direct interview with them.

In extreme synthesis, we outline that the occurrence of psychiatric disorders is high both in children with headache and their parents, but a very different pattern seems to characterize migraine (familial co-transmission of migraine and Psi-Co?) if compared to non-migraine headache.

Conflict of interest None.

\section{References}

1. Montagna P (2000) Molecular genetics of migraine headaches: a review. Cephalalgia 20:3-14

2. Kors EE, Vanmolkot KRJ, Haan J, Frants RR, Van den Maagdenberg AMJM, Ferrari M (2004) Recent findings in headache genetics. Curr Opin Neurol 17(3):283-288

3. Wessman M, Terwindt GM, Kaunisto MA, Palotie A, Ophoff RA (2007) Migraine: a complex genetic disorder. Lancet Neurol 6:521-532

4. Colson NJ, Fernandez F, Lea RA, Griffiths LR (2007) The search for migraine genes: an overview of current knowledge. Cell Mol Life Sci 64:331-344

5. Van de Ven RC, Kaja S, Plomp JJ et al (2007) Genetic models of migraine. Arch Neurol 64:643-646

6. Van de Maagdenberg AM, Haan J, Terwindt GM, Ferrari MD (2007) Migraine: gene mutations and functional consequences. Curr Opin Neurol 20:299-305

7. Russell MB (2007) Genetics in primary headaches. J Headache Pain 8:190-195

8. Russell MB (1997) Genetic epidemiology of migraine and cluster headache. Cephalalgia 17:683-701

9. Ferrari MD (1998) Migraine. Lancet 351:1043-1051

10. Vahlquist B (1955) Migraine in children. Int Arch Allergy 7:348355

11. Congdon PJ, Forsythe WI (1979) Migraine in childhood: a study of 300 children. Dev Med Child Neurol 21:209-216

12. Prensky AL, Sommer D (1979) Diagnosis and treatment of migraine in children. Neurology 21:506-510

13. Elser JM, Woody RC (1990) Migraine headache in the infant and young child. Headache 30:366-368

14. Messinger HB, Spierings EL, Vincent AJ, Lebbink J (1991) Headache and family history. Cephalalgia 11:13-18

15. Russell MB, Olesen J (1995) Increased familial risk and evidence of a genetic factor in migraine. Br Med J 311:541-544

16. Ducros A, Tournier-Lasserve E, Bousser MG (2002) The genetics of migraine. Lancet Neurol 1:285-293

17. Mulder EJ, Van Baal Gaist D et al (2003) Genetic and environmental influences on migraine: a twin study across six countries. Twin Res 6(5):422-431

18. Larsson B, Bille B, Pedersen NL (1995) Genetic influences in headache: a Swedish twin study. Headache 35:513-519

19. Ziegler DK, Hur YM, Bouchard TJ Jr, Hassanein RS, Barter R (1998) Migraine in twins raised together and apart. Headache $38: 417-422$
20. Gervil M, Ulrich V, Kaprio J, Olesen J, Russell MB (1999) The relative role of genetic and environmental factors in migraine without aura. Neurology 53:995-999

21. Cao M, Zhang S, Wang Y, Wang W (2002) Personality traits in migraine and tension-type headache:a five factor model study. Psychopathology 35:254-258

22. Bensenor IM, Tofoli LF, Andrade L (2003) Headache complaints associated with psychiatric comorbidity in a population-based sample. Braz J Med Biol Res 36:1425-1432

23. Zwart JA, Dyb G, Hagen K, Odegard KJ, Dahl AA, Bovim G, Stovner LJ (2003) Depression and anxiety disorders associated with headache frequency The Nord-Trondelag Health Study. Eur J Neurol 10:147-152

24. Headache Classification Subcommittee of the International Headache Society: The International Classification of Headache Disorders (2004) Cephalalgia 24(1):1-160

25. Russell MB, Fenger K, Olesen J (1996) Family history of headache disorders: direct versus indirect information. Cephalalgia $16: 156-160$

26. Tabachnick BG, Fidell LS (2006) Using multivariate statistics. Allyn \& Bacon Inc., Needham Heights

27. Østergaard S, Russell MB, Bendsten L, Olesen J (1997) Comparison of first-degree relatives and spouses of people with chronic tension-type headache. BMJ 3(14):1092-1093

28. Russell MB (2000) Complex segregation analysis in headache disorders. In: Genetic of headache disorders. In: Olesen J, Bousser MG (eds) Lippincott Williams \& Wilkins, Philadelphia, pp 75-82

29. Merikangas KR, Merikangas JR, Angst J (1993) Headache syndromes and psychiatric disorders: association and familial transmission. J Psychiatr Res 27:197-210

30. Guidetti V, Galli F, Fabrizi P, Napoli L, Giannantoni AS, Bruni O, Trillo S (1998) Headache and psychiatric comorbidity: clinical aspects and outcome in an 8-year follow-up study. Cephalalgia 7(18):455-462

31. Karwautz A, Wöber C, Lang T et al (1999) Psychosocial factors in children and adolescents with migraine and tension-type headache: a controlled study and review of the literature. Cephalalgia 19:32-43

32. Galli F, D'Antuono G, Tarantino S, Viviano F, Borrelli O, Chirumbolo A, Cucchiara S, Guidetti V (2007) Headache and recurrent abdominal pain: a controlled study by the means of the Child Behaviour Checklist (CBCL). Cephalalgia 27(3):211-219

33. Williams LJ, Jacka FN, Pasco JA et al (2006) Depression and pain: an overview. Acta Neuropsychiatrica 18(2):79-87

34. Arnstein P, Caudill M, Mandle CL et al (2004) Self efficacy as a mediator of the relationship between pain intensity, disability and depression in chronic pain patients. Pain 80(3):483-491

35. Verma S, Gallagher RM (2001) The psychopharmocologic treatment of depression and anxiety in the context of chronic pain. Curr Pain Headache Rep 6(1):30-39

36. Gallagher RM, Verma S (1999) Managing pain and comorbid depression: a public health challenge. Sem Clin Neuropsychiatry 4(3):203-220

37. Blackburn-Munro G, Blackburn-Munro RE (2001) Chronic pain, chronic stress and depression: coincidence or consequence. J Neuroendocrinol 13(12):1009-1023

38. Gonda X, Rihmer Z, Juhasz G, Zsombok T, Bagdy G (2007) High anxiety and migraine are associated to $\mathrm{s}$ allele of the 5HTTLPR gene polymorphism. Psychiatr Res 149:261-266

39. Montagna P, Cevoli S, Marzocchi N et al (2003) The genetics of chronic headaches. Neurol Sci 24(Suppl 2):S51-S56

40. Caldecott-Hazard S, Morgan DG, De Leon-Jones F, Overstreet DH, Janowsky D (1991) Clinical and biochemical aspects of depressive disorders: II. Transmitter/receptor theories. Synapse 9:251-301 
41. Peroutka SJ, Price SC, Wilhoit TL, Jones KW (1998) Comorbid migraine with aura, anxiety, and depression is associated with dopamine D2 receptor (DRD2) NcoI alleles. Mol Med 4:14-21

42. Jarman J, Fernandez M, Davies PT et al (1990) High incidence of endogenous depression in migraine: confirmation by tyramine test. J Neurol Neurosurg Psychiatry 53:573-575

43. Molgat CV, Patten SB (2005) Comorbidity of major depression and migraine-a Canadian population-based study. Can J Psychiatry 50:832-837

44. Breslau N, Schultz LR, Stewart WF et al (2000) Headache and major depression: is the association specific to migraine? Neurology 54:308-313

45. Oedegaard KJ, Angst J, Neckelmann D et al (2005) Migraine aura without headache compared to migraine with aura in patients with affective disorders. J Headache Pain 6:378-386

46. Smitherman TA, Maizels M, Penzien DB (2008) Headache chronification: screening and behavioral management of comorbid depressive and anxiety disorders. Headache 48:45-50

47. Mattsson P, Ekselius L (2002) Migraine, major depression, panic disorder, and personality traits in women aged $40-74$ years: a population-based study. Cephalalgia 22:543-551

48. Merikangas KR, Risch NJ, Merikangas JR et al (1988) Migraine and depression: association and familial transmission. J Psychiatr Res 22:119-129

49. Silberstein SD, Lipton RB, Breslau N (1995) Migraine: association with personality characteristics and psychopathology. Cephalalgia 15:337-369

50. Hung CI, Wang SJ, Hsu KH (2005) Risk factors associated with migraine or chronic daily headache in out-patients with major depressive disorder. Acta Psychiatr Scand 111:310-315

51. Mongini F, Rota E, Deregibus A et al (2006) Accompanying symptoms and psychiatric comorbidity in migraine and tensiontype headache patients. J Psychosom Res 61:447-451

52. Beghi E, Allais G, Cortelli D et al (2007) Headache and anxietydepressive disorder comorbidity: the HADAS study. Neurol Sci 28:S217-S219
53. Torelli P, Lambru G, Manzoni GC (2006) Psychiatric comorbidity and headache: clinical and therapeutical aspects. Neurol Sci 27:S73-S76

54. Oedegaard KJ, Neckelmann D, Mykletun A et al (2006) Migraine with and without aura: association with depression and anxiety disorder in a population-based study. The HUNT Study. Cephalalgia $26: 1-6$

55. Smitherman TA, Baskin SM (2008) Headache secondary to psychiatric disorders. Curr Pain Headache Rep 12(4):305-310

56. Lipchik GL, Penzien DB (2004) Psychiatric comorbidities in patients with headaches. Seminars in Pain Medicine, vol 2, No. 2

57. Merikangas KR, Fenon B, Ramadan NM (1996) Comorbidity and migraine. Semin Headache Manage 1(4):1-10

58. Pakalnis A, Gibson J, Colvin A (2005) Comorbidity of psychiatric and behavioral disorders in pediatric migraine. Headache 45(5):590-596

59. Barton-Donovan K, Blanchard EB (2005) Psychosocial aspects of chronic daily headache. J Headahce Pain 6(1):30-39

60. Pine DS, Cohen P, Brook J (1996) The association between major depression and headache: results of a epidemiologic study in youth. J Child Adolesc Psychopharmacol 6:153-164

61. Sillberstein SD (2001) Shared mechanism and comorbidities in neurologic and psychiatric disorders. Headache 41(Suppl 1):11-17

62. Verbeeck WJC, Berk M, Paiker J, Jersky B (2001) The prolactin response to sulpiride in major depression:the role of the D2 receptor in depression. Eur Neuropsychopharmacol 11(3):215220

63. Parsey RV, Oquendo MA, Zea-Ponce Y et al (2001) Dopamine D2 receptor availability and amphetamine-induced dopamine release in unipolar depression. Biol Psychiatry 50:313-322

64. Breslau N, Davis GC, Andreski P (1991) Migraine, psychiatric disorders and suicide attempts: an epidemiological study of young adults. Psychiatry Res 37:11-23

65. Glover V, Jarman J, Sandler M (1993) Migraine and depression: biological aspects. J Psychiatr Res 2:223-231 